\title{
Análisis neotectónico y paleosísmico de la falla Loma Negra Oriental, frente orogénico de la Precordillera Central, Argentina
}

\author{
Neotectonic and paleoseismic analysis of the Loma Negra Oriental fault, orogenic front of the \\ Central Precordillera, Argentina
}

Flavia Tejada ${ }^{1,2, *}$, Martin Rothis ${ }^{1,2}$, M. Romina Onorato ${ }^{1,2}$, Pablo A. Blanc ${ }^{1,2}$, Laura Perucca ${ }^{1,2}$, Franck A. Audemard M. ${ }^{3}$, Nicolás Vargas

${ }^{1}$ Gabinete de Neotectónica y Geomorfología (INGEO-FCEFN), Universidad Nacional de San Juan, Ignacio de la Roza 590 (O), 5400, Rivadavia, San Juan, Argentina.

${ }^{2}$ Grupo Geología del Cuaternario (CIGEOBIO-UNSJ-CONICET), Ignacio de la Roza 590 (O), 5400, Rivadavia, San Juan, Argentina.

${ }^{3}$ Universidad Central de Venezuela, Ciudad Universitaria, Municipio Libertador, Caracas, Venezuela. flaviatejada@gmail.com
* Autor para correspondencia: (F. Tejada)

\section{RESUMEN}

La falla Loma Negra Oriental (FLNOr) se localiza en el frente orogénico de Precordillera Central, caracterizado por cabalgamientos de rumbo N-S y vergencia hacia el este. La misma bordea el flanco oriental del braquianticlinal de Loma Negra, un pliegue por propagación de falla que deforma las rocas neógenas y los depósitos cuaternarios en el piedemonte oriental de la Sierra de Talacasto. Las fallas de rumbo submeridional identificadas en el pliegue afectan depósitos cada vez más recientes hacia el este, lo que evidenciaría el avance de la deformación andina en esa dirección. En el sector norte de la falla Loma Negra Oriental, una exposición natural permitió determinar su cinemática y mostró depósitos asociados con eventos de desplazamiento discretos. La estructura constituye un cabalgamiento con orientación $130^{\circ}$, de bajo ángulo de inclinación $\left(22^{\circ} \mathrm{SO}\right)$ que afecta unidades aluviales del Holoceno temprano (8.700 \pm 1.370 años AP). Se determinó la morfología de las escarpas asociadas a esta estructura a través de perfiles topográficos de detalle transversales al rumbo de la misma. Dichos perfiles permitieron identificar dos escarpas de falla de orden métrico (entre 0.9 y $3.1 \mathrm{~m}$ ) que sugeriría la ocurrencia de varios eventos sísmicos. La falla continuaría tanto hacia el norte como al sur como una estructura ciega (soterrada) que limitaría todo el flanco oriental del braquianticlinal con una longitud de al menos 16,5 km. Con base en la medición de las escarpas, la longitud de ruptura superficial y subsuperficial, y a un análisis paleosísmico efectuado en una exposición natural, en la que se obtuvo un desplazamiento vertical total de $0,9 \pm 0.1 \mathrm{~m}$ $(\sim 0,4 \mathrm{~m}$ para el último evento y $\sim 0,5 \mathrm{~m}$ para el más antiguo) y desplazamiento cosísmico sobre el plano de la falla de $\sim 1,16 \pm 0,15 \mathrm{~m}$, se sugiere la ocurrencia de dos eventos durante el Pleistoceno tardío y Holoceno. Es por ello que puede considerarse esta estructura como una potencial fuente sismogénica capaz de producir un sismo máximo de magnitud $\mathrm{Mw}>6,5$ con una tasa de retorno de $\sim 9.000$ años. Estos datos son relevantes para la estimación del peligro sísmico de las principales obras civiles y centros poblados de la provincia de San Juan (>800.000 habitantes). Universidad Nacional Autónoma de México.
Palabras clave: cabalgamiento, falla activa, Holoceno, peligro sísmico, Andes Centrales.

\section{ABSTRACT}

The reverse fault known as Loma Negra Oriental is located on the orogenic front of the Central Precordillera, characterized by $\mathcal{N}-S$ trending thrusts with eastern vergence. This fault limits the eastern flank of the Loma Negra brachianticline, a fault propagation fold that deforms Neogene rocks and Quaternary deposits outcropping on the eastern piedmont of the Sierra de Talacasto. The faults related to this fold trend $\mathcal{N}-S$ and affect progressively younger deposits to the east, showing the advance of the Andean deformation in that direction. In the northern section of the Loma Negra Oriental Fault, a natural exposure showes deposits associated with single-event displacements, allowing us to determine its kinematics. The Loma Negra Oriental thrust showes a NNW trend $\left(130^{\circ}\right)$ and dips with low angle $\left(22^{\circ} \mathrm{SW}\right)$ affecting recent alluvial deposits of early Holocene age $(8,700 \pm 1,370$ years $B P)$. To characterize the morphology of the scarps associated with this fault, we constructed detailed topographic profiles transverse to the analysed structure. Two scarps of $0.9 \mathrm{~m}$ and $3.1 \mathrm{~m}$ high were recognized, suggesting several seismic events. The fault seems to continue to the north and south as a blind (buried) structure that limits the entire eastern flank of the brachianticline, with a length of at least $16.5 \mathrm{~km}$. Based on the scarps measurement, the surface and subsurface rupture extension, and the paleoseismic analysis of a natural exposure, with a total vertical slip of $0.9 \pm 0.1 \mathrm{~m}(\sim$ $0.4 \mathrm{~m}$ for the last event and $\sim 0.5 \mathrm{~m}$ for the penultimate) and a dip-slip per event of $1.16 \pm$ $0.15 \mathrm{~m}$, we suggest the occurrence of two seismic events during the Late Pleistocene-Holocene. In this way, we consider this structure as a potential seismogenic source which could generate a maximum probable earthquake of magnitude Mw 6.5 or larger, with an estimated recurrence period of -9,000 years, posing a threat to infrastructure and populated areas of the province of San Fuan (>800,000 inhabitants).

Keywords: thrust, active fault, Holocene, seismic hazard, Central Andes. 


\section{Introducción}

El área de estudio se ubica en la región centro-oeste de Argentina (Figura 1a), en la Precordillera Central, donde surca la provincia de San Juan. Esta región presenta una elevada actividad sísmica debido a la subducción subhorizontal de la placa de Nazca por debajo de la placa Sudamericana a profundidades entre 90 y $110 \mathrm{~km}$ (Anderson et al., 2007) (Figura 1b). La zona se caracteriza por la ocurrencia de sismos corticales de intraplaca, de magnitudes variables, algunos llegando a ser terremotos destructivos asociados a deformaciones del terreno (Perucca y Paredes, 2003; Alvarado y Beck, 2006).

El piedemonte oriental de la sierra de Talacasto, en el ámbito de la Precordillera Central $\left(30^{\circ}\right.$ $47^{\prime}-30^{\circ} 57^{\prime} \mathrm{S}$ y $\left.68^{\circ} 37^{\prime}-68^{\circ} 46^{\prime} \mathrm{O}\right)$ presenta evidencias de deformación en rocas paleozoicas y del Neógeno, cabalgamientos con vergencia oriental y pliegues por propagación de falla (Allmendinger et al., 1990) (Figura 1c). Sin embargo, algunos trabajos describen además deformaciones cuaternarias tales como las contribuciones de Perucca y Vargas (2014) y Perucca et al. (2014). Por otro lado, Ocaña et al. (2017) realizaron un estudio geomorfológico al sur del área de estudio y Tejada et al. (2018) efectuaron un análisis morfotectónico en el que obtuvieron diversos índices en las cuencas fluviales del borde oriental de dicha sierra, también al sur de la estructura braquianticlinal.

La falla Loma Negra Oriental (FLNOr), objeto de este trabajo, es un cabalgamiento que afecta a depósitos aluviales del Cuaternario, cuya escarpa posee la cara libre al este y margina el flanco este de la estructura braquianticlinal de Loma Negra, constituyendo el frente de corrimiento activo en este sector de Precordillera Central (Perucca et al., 2015).

Se pretende a través de un análisis combinado (perfiles topográficos de detalle, descripción paleosísmica de una exposición natural, uso de fórmulas empíricas) mejorar el conocimiento del comportamiento sismogénico de esta estructura cercana a las ciudades de San Juan al sur y Jáchal al norte, y de esta manera reducir los niveles de incertidumbre en la evaluación del peligro sísmico potencial de esta falla activa.

Así, el propósito de este trabajo es incrementar el conocimiento de las estructuras activas ubicadas en el frente de cabalgamiento de Precordillera Central a estas latitudes y caracterizar la FLNOr, como fuente sismogénica potencial cercana a los principales centros poblados del centro-oeste argentino.

\section{Marco geológico}

Entre los $29^{\circ}$ y $33^{\circ} \mathrm{S}$, la placa de Nazca se introduce por debajo de la Sudamericana a una velocidad de 6,3 cm/año (e.g, Ramos, 1988; Kendrick et al., 2003) con azimut de $\sim 78^{\circ}$ (Vigny et al., 2009) y un ángulo subhorizontal (entre $5^{\circ}$ y $10^{\circ}$ ). Esta geometría de placa plana es atribuida a la subducción de la dorsal Juan Fernández (Figura 1b) (e.g., Pilger, 1981; Anderson et al., 2007) y se caracteriza por la presencia de importantes estructuras tectónicas activas y por el desarrollo de un frente orogénico que pliega incluso los depósitos aluviales cuaternarios (Bastías, 1985; Costa et al., 2000; Perucca et al., 2013; Perucca y Vargas, 2014; Audemard et al., 2016; Costa et al., 2020). Además se destacan los cabalgamientos de las secuencias neógenas sobre esos depósitos de piedemonte (Ramos, 1997). Ortiz y Zambrano (1981) dividieron la Precordillera en tres dominios de acuerdo a su estilo estructural, a los que denominaron Precordillera Occidental, Central y Oriental. La Precordillera Central, donde se desarrolla la presente investigación, está constituida por cordones montañosos de orientación meridional, que se extienden a lo largo de toda la provincia de San Juan. Posee un estilo de deformación de una faja plegada y corrida de piel delgada (thin skinned fold and thrust belt) con una marcada vergencia hacia el este (Jordan et al., 1984, 1993; Ramos, 1988, 1999; Ramos et al., 1997; Costa et al., 2000; Kay y Mpodozis, 2002). Estos cabalgamientos forman un abanico imbricado hacia el antepaís (Boyer y Elliot, 1982), donde las 


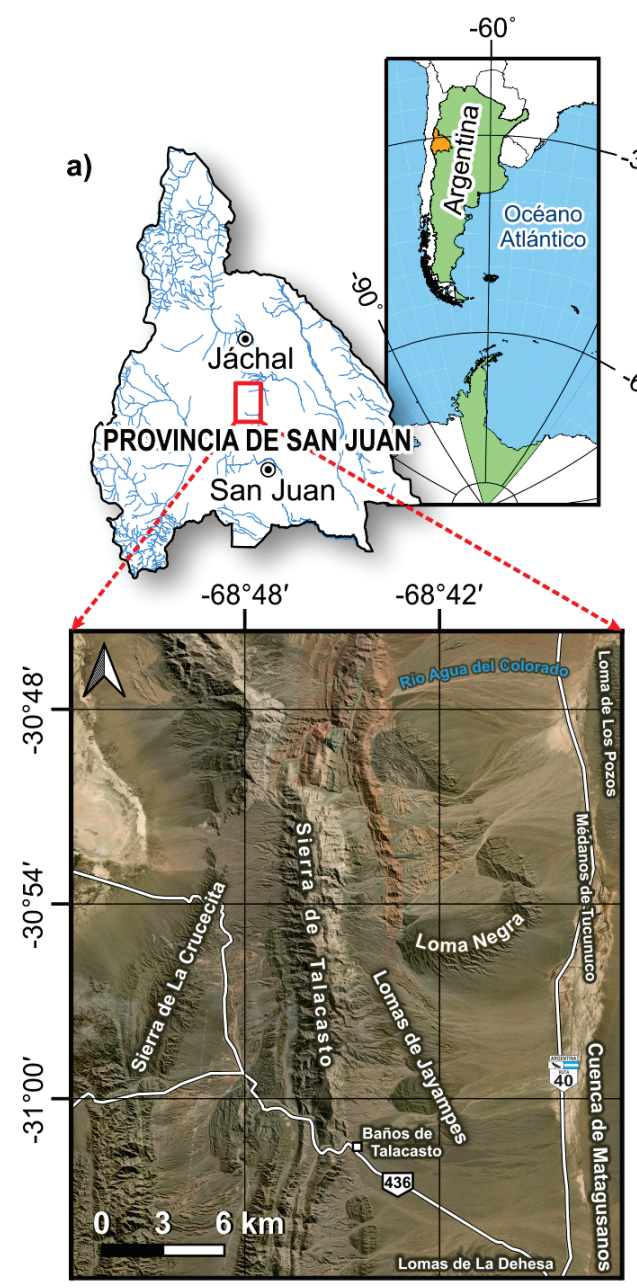

\section{REFERENCIAS}
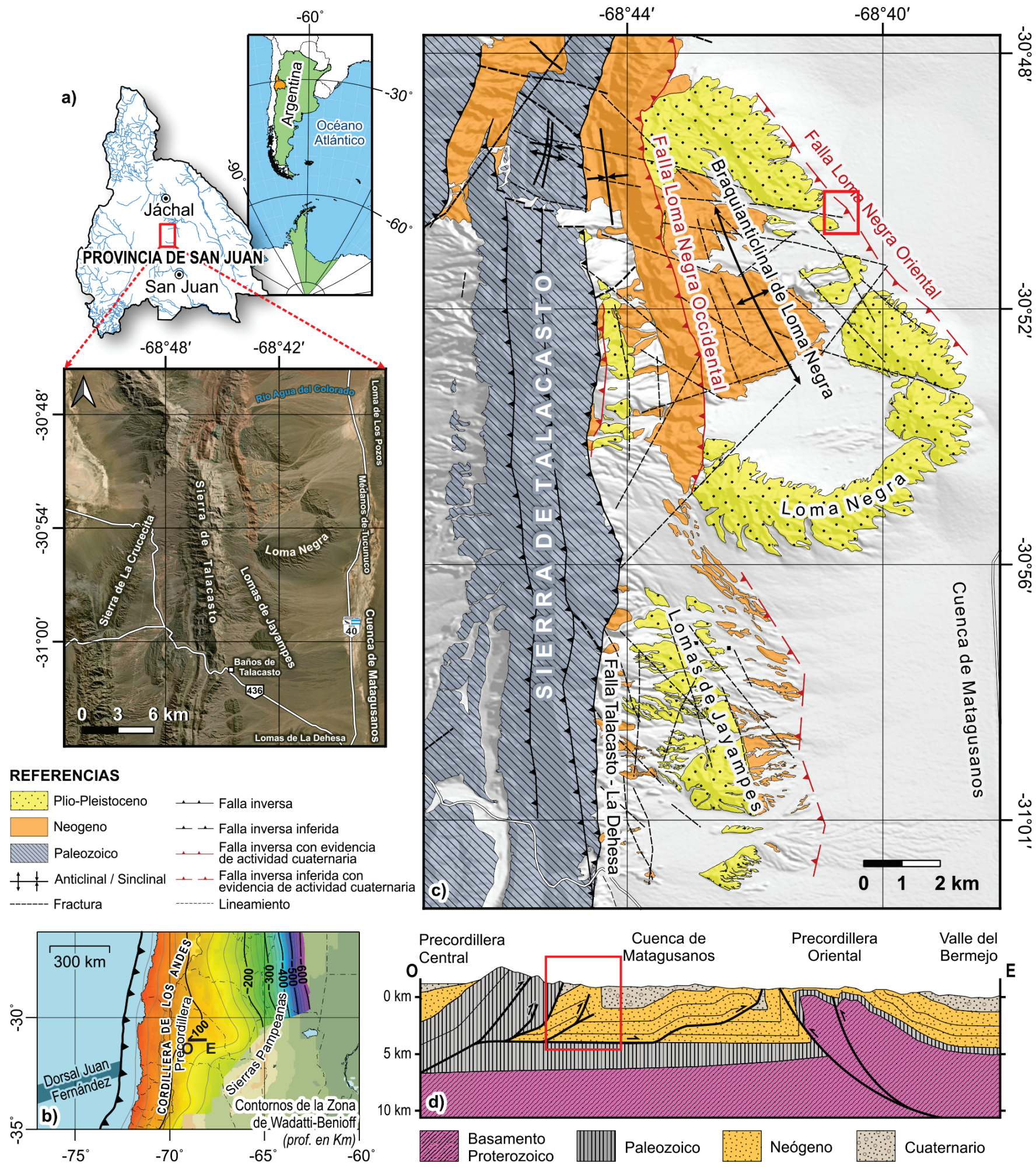

Figura 1 a) Ubicación del área de estudio (recuadro rojo) e imagen satelital del braquianticlinal de Loma Negra. b) Mapa de ubicación de la zona de estudio en relación a las placas de Nazca y Sudamericana y la Dorsal de Juan Fernández con la ubicación del perfil estructural a la latitud de análisis (O-E). c) Mapa geológico del área de estudio. El recuadro rojo indica el sector en el que se efectuaron los perfiles topográficos de detalle y el análisis paleosísmico. d) Perfil estructural que muestra la relación entre el frente orogénico de Precordillera Central, con el frente orogénico de Precordillera Oriental (modificado de Siame et al., 2005). El recuadro señala el sector de análisis. 
láminas imbricadas antiguas se disponen sobre las más nuevas, generando el aumento progresivo de las inclinaciones originales e incluso el vuelco de los planos de cabalgamiento (von Gosen, 1992). Está constituida por al menos cuatro y hasta seis cabalgamientos principales con su nivel de despegue en la secuencia cambro-ordovícica (Allmendinger et al., 1990), fallas fuera de secuencia y estructuras de interferencia resultantes de la interacción con la estructuración de la Precordillera Oriental, caracterizada por fallas de alto ángulo de vergencia occidental (Zapata y Allmendinger, 1996) (Figura 1d). La estratigrafía en el piedemonte de la sierra de Talacasto está caracterizada por rocas de edad ordovícica (calizas y dolomías) y neógena (conglomerados, sabulitas, areniscas, limolitas y limoarcilitas). El Cuaternario está representado principalmente por aglomerados, fanglomerados y depósitos aluviales y coluviales provenientes de los sectores serranos (Furque et al., 1998; Milana, 2003) (Figura 1c).

La elevada sismicidad de intraplaca y la notable actividad neotectónica a esta latitud también es consecuencia de la subducción subhorizontal de la placa de Nazca por debajo de la Sudamericana, que traslada la deformación hacia el antepaís (Ramos et al., 1986). Siame et al. (2005) señalaron que, debido a la convergencia oblicua entre estas placas, la región además de estar sometida a tectónica contractiva, habría estado dividida a nivel cortical entre movimientos de deslizamiento de rumbo e inversos durante el Plioceno-Cuaternario. En la zona de Matagusanos-Talacasto-Tucunuco, el eje de esfuerzos $\sigma 1$ es subhorizontal y presenta una orientación $\mathrm{N} 50^{\circ} \mathrm{E}$ (Figura 2a). Otras contribuciones han demostrado que la deformación transpresional tuvo lugar en Precordillera durante el Mioceno (Japas, 1998; Ré et al., 2001; Siame et al., 2005; Álvarez-Marrón et al., 2006; Alcacer y Perucca, 2017). Para el segmento de subducción horizontal pampeano, Japas et al. (2016) discriminaron fajas transpresivas sinestrales que estarían vinculadas a la convergencia oblicua de las placas y a la activación de estructuras sinestrales de orientación NO.

\subsection{MARGO NEOTEGTÓNICO}

Entre las dos unidades morfoestructurales de Precordillera Central y Oriental se desarrolla una depresión tectónica elongada de rumbo N-S denominada corredor tectónico MatagusanosMaradona-Acequión, correspondiente a los valles homónimos (Perucca, 1990; Zapata y Allmendinger, 1996; Siame et al., 2006; Perucca et al., 2013; Audemard et al., 2016) y que se extiende desde los médanos de Tucunuco en el norte (Figura 2b) hasta el límite con la provincia de Mendoza en el sur. En el valle de Matagusanos, ubicado al norte del río San Juan, se reconocieron fallas con actividad tectónica cuaternaria en los dos bordes que limitan este valle longitudinal por el oeste y el este (Figura 2b). Por el oeste, se destaca el sistema de fallas Lomitas de Matagusanos (Falla Lomitas de Matagusanos, los Blanquitos y Lomitas oriental) (Paredes y Perucca, 2000). Estas fallas de rumbo $\mathrm{N}-\mathrm{S}$ son subparalelas, inversas, de alto ángulo $\left(50^{\circ}-75^{\circ}\right)$ y vergencia occidental (Paredes et al., 1996, 1997; Paredes y Perucca, 1999, 2000; Costa et al., 1999, 2000) con escarpas a contrapendiente que afectan a abanicos aluviales cuaternarios provenientes de la sierra de La Dehesa. Hacia el sur las fallas pierden su expresión cuaternaria y cortan los estratos neógenos, cuyo rumbo es NO. Por otra parte, hacia el oeste del sistema de fallas Lomitas de Matagusanos, se ubica la falla Lomas del Salto, la cual buza al este entre $70^{\circ}$ y $75^{\circ}$ (Paredes y Perucca, 2000) y también afecta depósitos aluviales cuaternarios y plio-pleistocenos. Paredes y Perucca (2000) efectuaron la datación de un nivel de travertino en el plano de la falla los Blanquitos,

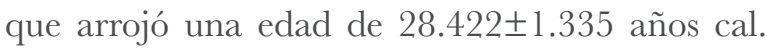
AP. Estos autores encontraron evidencia de reactivación posterior, por lo que sugirieron actividad tectónica durante el Pleistoceno tardío-Holoceno (Perucca y Vargas, 2014).

Estas estructuras rectilíneas, con vergencia occidental y que parecen estar controladas por la estratificación del Neógeno han sido consideradas por Costa et al. (1999) como fallas interestratales (flexural-slip faults). Sin embargo, otros autores 


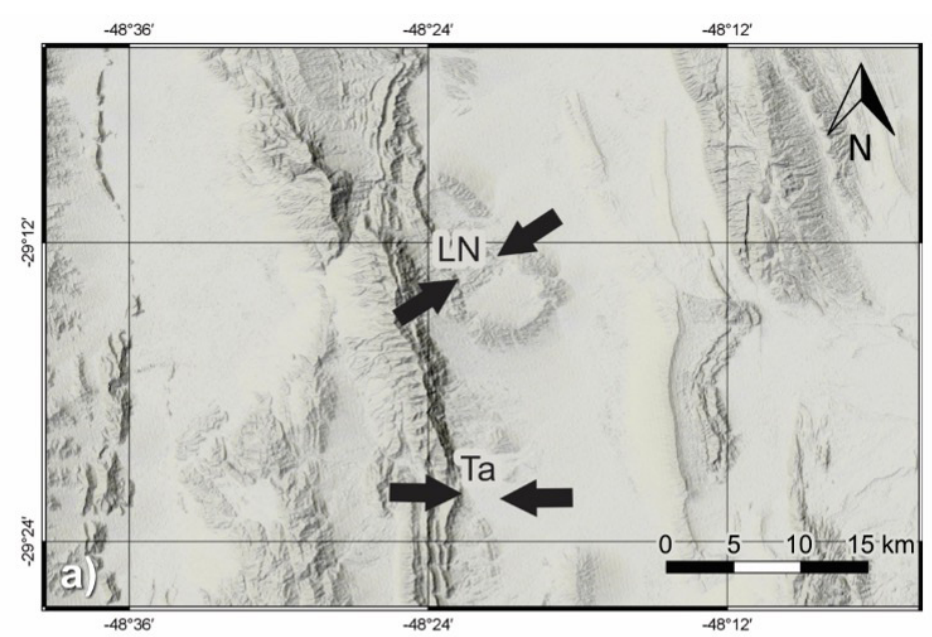

LN: Loma Negra - Ta: Talacasto

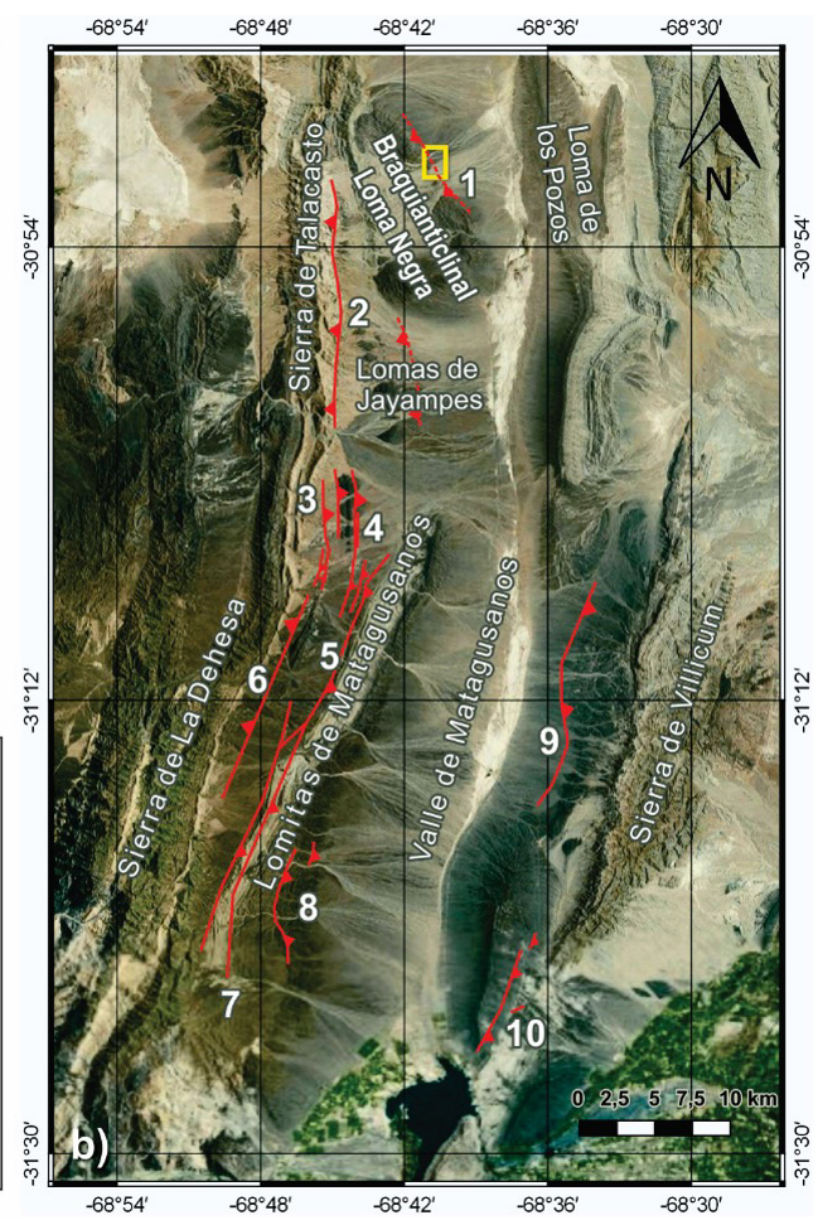

1 - Falla Loma Negra Oriental
2 - Falla Talacasto
3 - Falla Lomas del Salto
4 - Falla Blanquitos
5 - Falla Lomitas de Matagusanos
6 - Falla La Dehesa
7 - Falla Blanquitos este
8 - Falla Lomitas Oriental
9 - Falla Villicum Occidental
10 - Falla Loma de Las Tapias
Figura 2 a) Modelo de elevación digital del área de estudio con la ubicación de los ejes de esfuerzos en la zona de la Loma Negra y
Talacasto (Modificado de Siame et al., 2005). b) Imagen satelital del Corredor Tectónico Matagusanos con la localización de las fallas con actividad tectónica cuaternaria (modificado de Perucca et. al., 2013). El recuadro amarillo indica la ubicación de la exposición natural analizada sobre el trazo de la FLNOr.

tales como Paredes y Perucca (2000) y Perucca $e t$ al. (2013) consideraron que estas estructuras no constituirían fallas con deslizamiento flexural ya que hacia el sur las mismas no coinciden con el rumbo de los estratos del Neógeno y en cambio lo cortan. Sugirieron además que estas fallas con alto ángulo y vergencia occidental permitirían ubicar el eje de la zona triangular en este sector de la depresión aunque no se descarta que constituyan retrocorrimientos con vergencia occidental.

La falla La Dehesa (Bastías, 1985) posee 20 $\mathrm{km}$ de longitud, orientación N-S, inclina $60^{\circ} \mathrm{O}$ y coloca sedimentitas neógenas sobre depósitos aluviales asignados al Pleistoceno (Perucca et al., 2013). Estas fallas de vergencia oriental ubicadas en el borde occidental del corredor tectónico, delimitarían el frente de cabalgamientos de Precordillera Central.

En el borde oriental del corredor, el frente de Precordillera Oriental está representado por la falla Villicum Occidental y la falla Loma de Las Tapias (Bastías et al., 1984; Bastías, 1985; Siame et al., 2002; Perucca y Vargas, 2014). Ambas constituyen secciones del sistema de falla regional Villicum-Zonda. La falla Villicum Occidental tiene tendencia NNE, es inversa de alto ángulo y vergencia occidental. La evidencia de actividad tectónica cuaternaria son las escarpas de rumbo N-S con cara libre al oeste y los depósitos aluviales del Pleistoceno-Holoceno provenientes de la 
Sierra de Villicum que se encuentran basculados hacia el este, esto es, poseen una pendiente anómala contraria a la original (Perucca et al., 2013, Perucca y Vargas, 2014). La falla Loma de Las Tapias, también de vergencia occidental, tiene una longitud de $9 \mathrm{~km}$ con azimut entre $175^{\circ}$ y $200^{\circ}$, las estrías encontradas en trincheras naturales sugieren para esta estructura una significativa componente de rumbo dextral (Perucca et al., 2013). Las fallas mencionadas evidencian la influencia de la tectónica activa sobre los elementos del paisaje, dando como resultado cuencas de drenaje asimétricas y anomalías en los cauces fluviales (Blanc et al., 2020). Siame et al. (2002, 2006) sugirieron una edad mínima de $1.900 \pm 0.800$ 10Be-años para el nivel aluvial reciente y de $6.900 \pm 1.000$ y

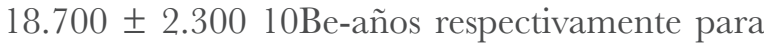
dos niveles aluviales sobreelevados más antiguos. Estimaron una tasa de levantamiento de $0,7 \pm 0,3$ $\mathrm{mm} /$ año y de acortamiento de $0,8 \pm 0,5 \mathrm{~mm} /$ año, con un intervalo de recurrencia de $2.400( \pm 1.500)$ años.

En el área de estudio, el piedemonte oriental de la sierra de Talacasto, Perucca et al. (2014) identificaron estructuras con actividad tectónica cuaternaria tales como la falla Talacasto-La Dehesa, inversa de alto ángulo $\left(70^{\circ} \mathrm{O}\right)$ y rumbo $\mathrm{N}-\mathrm{S}$, que flanquea por el este a la sierra de Talacasto, elevando las
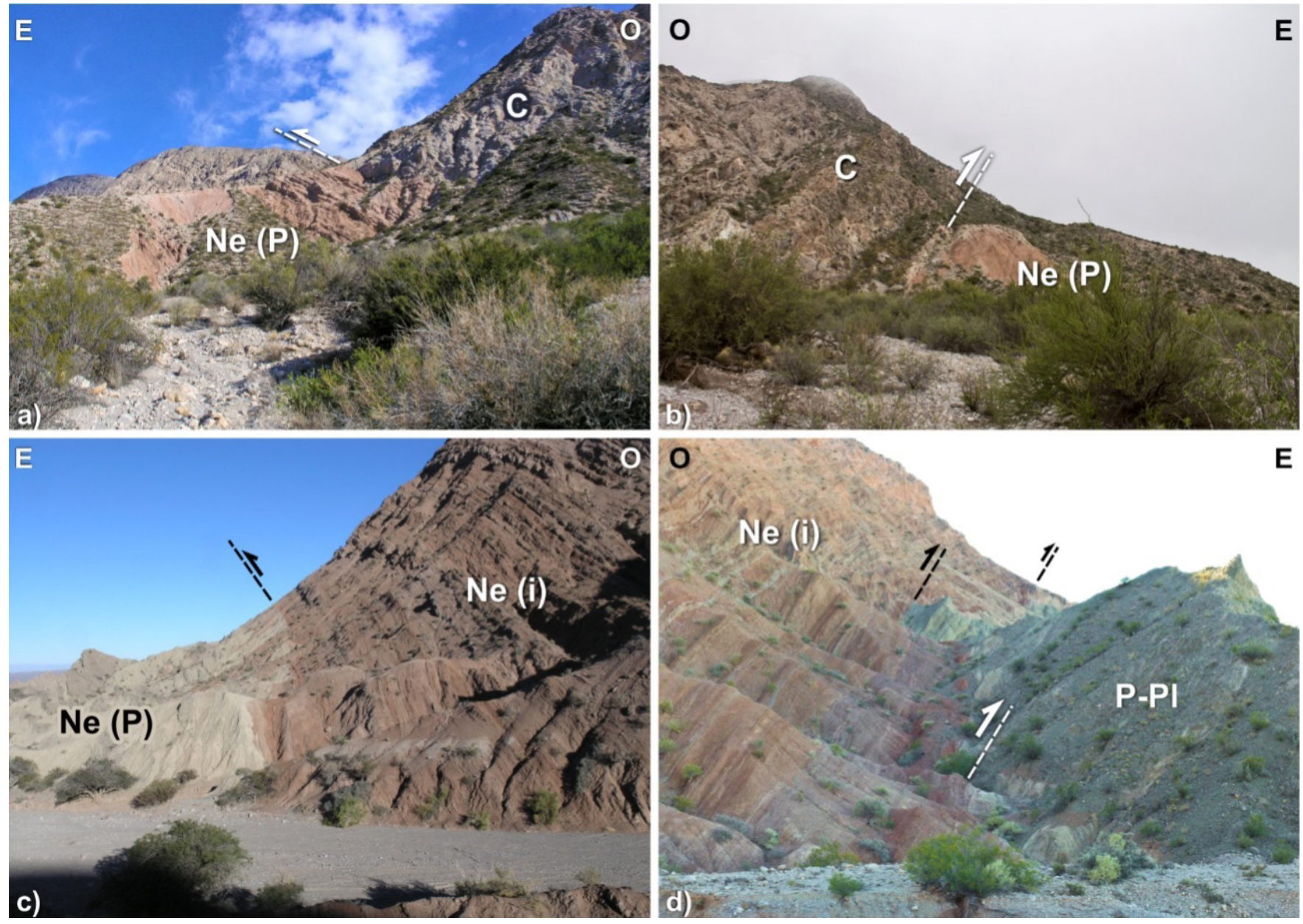

Figura 3 a) Vista al sur de la falla Talacasto, inversa y con vergencia al este. La falla dispone calizas de edad ordovícica (C) sobre sedimentitas pliocenas: Ne (P). b) Vista al norte de la falla Talacasto que coloca rocas calcáreas (C) sobre depósitos neógenos: Ne (P). C) Vista al sur de la falla Loma Negra Occidental, inversa y con vergencia al este. Esta falla dispone rocas asignadas por Perucca et al. (2014) al Neógeno indiferenciado: Ne (i) sobre rocas pliocenas $\mathrm{Ne}$ (P). d) Vista hacia el norte de la falla Loma Negra Occidental que coloca rocas del Neógeno indiferenciado: $\mathrm{Ne}(\mathrm{i})$, sobre conglomerados plio-pleistocenos (P-PI). 
calizas ordovícicas que componen dicha serranía sobre sedimentitas del Neógeno (Figuras 1c, 3a y 3b). También mediante evidencias geomorfológicas tales como abanicos sobreelevados y con pendientes anómalas, cauces colgados, etc., sugirieron la existencia de actividad tectónica cuaternaria en el sector. Además, definieron la Loma Negra como un braquianticlinal con eje $\mathrm{NO}\left(\mathrm{N} 140^{\circ} \mathrm{E}\right)$, de vergencia oriental, con el núcleo formado por bancos de areniscas y limolitas del Mioceno superior-Plioceno inferior y sus flancos compuestos por estratos conglomerádicos más competentes, correspondientes al Plioceno-Pleistoceno inferior (Figura 1c). El flanco occidental del braquianticlinal está truncado por una falla inversa de rumbo meridional, alto ángulo $\left(70^{\circ}\right)$ de inclinación hacia el SO y vergencia oriental a la que Perucca et al. (2014) denominaron falla Loma Negra Occidental (Figura 1c). En su tramo central, la falla dispone estos depósitos neógenos indiferenciados por encima de sedimentitas del Plioceno inferior (Figura 3c). En los extremos norte y sur del braquianticlinal, la falla coloca rocas asignadas por estos autores al Neógeno sobre conglomerados del Plio-Pleistoceno (Figura 3d). En el interior de esta estructura plegada, estos autores identificaron escarpas subparalelas, de rumbo submeridional, con la cara libre al oeste y a contrapendiente de la pendiente regional. Las fallas inversas de vergencia occidental y alto ángulo colocan los conglomerados del Plioceno-Pleistoceno sobre depósitos aluviales asignados al Pleistoceno tardío (Figuras 4 y 5a). La distribución espacial de la deformación cuaternaria en planos de fallas subparalelos, es típico de las estructuras flexodeslizantes (Yeats et al., 1997). Así, este tipo de fallas, de trazo rectilíneo y en apariencia controladas por la estratificación de los conglomerados del Plio-Pleistoceno han sido consideradas en otros sectores de la Precordillera Central (sistema de fallas Blanquitos) como estructuras controladas por mecanismos flexodeslizantes (Costa et al., 1999). Sin embargo, no descartaron que estas estructuras de vergencia occidental constituyan retrocabalgamientos con ángulos elevados cerca de la superficie y asociados al cabalgamiento
Loma Negra Oriental, de vergencia oriental. En el flanco oriental del braquianticlinal de Loma Negra, Perucca et al. (2014) identificaron la FLNOr, de vergencia oriental y rumbo submeridional, que afecta a una terraza fluvial a la cual asignaron tentativamente una edad holocena, objeto de estudio en este trabajo (Figuras 4 y 5b).

\section{Metodología}

En este estudio se efectuó, a partir de la interpretación de imágenes satelitales y tareas de campaña, el análisis de la geología del sector y de los principales rasgos geomorfológicos, los que permitieron confeccionar un mapa geológico del piedemonte oriental de la sierra de Talacasto. Las estructuras, fallas y pliegues con evidencia de actividad tectónica cuaternaria reconocidas en el área se indicaron en dicho mapa.

Además, se efectuaron tres perfiles topográficos de detalle aproximadamente ortogonales a las escarpas de la FLNOr. Los mismos se realizaron con un receptor GPS de alto rendimiento /SBAS L1, que cuenta con la tecnología de filtrado de la señal Everest. Las mediciones se obtuvieron utilizando los siguientes parámetros: el posicionamiento y la configuración de cada dispositivo en el modo manual, la selección de un registro a intervalos de 2 segundos, un ángulo de enmascaramiento de $10^{\circ}$ y realizar un seguimiento de los tiempos de 2 segundos. Para la recolección de campo, uno de los dispositivos (GPS) fue estacionado en un punto (utilizado como base), mientras que el otro se utilizó como móvil. El procesamiento de los datos de campo implica una corrección, utilizando el software que proporciona el equipo del sistema GPS diferencial.

Para estimar la edad de las escarpas identificadas, se siguió la metodología desarrollada por Wallace (1977) y Bucknam y Anderson (1979) que cuantifica algunos parámetros de la morfología de las escarpas tal como altura y ángulo máximo de talud y se los ingresa en ábacos de doble entrada. Si bien este método fue definido para el estudio de 
las fallas normales, se aplicó en este trabajo para una escarpa generada por una falla inversa, tal como fue propuesto por Sagripanti et al. (2003) y Villalba y Sagripanti (2014).

En una exposición natural ubicada en una terraza fluvial de la margen sur de un arroyo temporario proveniente de la sierra de Talacasto, se reconocieron 5 unidades litológicas que, de base a techo, se denominaron en forma consecutiva como Unidad S1 a S5. Al mismo tiempo, se analizó la estructura que afecta estas unidades.

En el laboratorio Datação, Comércio e Prestação de Serviços LTDA, San Pablo, Brasil, se efectuó el fechado por luminiscencia estimulada ópticamente (OSL), siguiendo el protocolo SAR de una muestra no disturbada de los materiales arenosos de uno de los niveles aluviales de la terraza afectados por la falla inversa con vergencia oriental oculta a la radiación solar

Del análisis paleosísmico de la exposición natural identificada en la sección norte de la falla, se determinaron la cantidad mínima de eventos sísmicos ocurridos, magnitud del sismo máximo probable, desplazamientos máximo y promedio para tal magnitud de acuerdo a las relaciones empíricas propuestas por Wells y Coppersmith (1994) e intervalo de recurrencia, lo que permitió estimar su potencial como fuente sismogénica. Los perfiles de alta resolución obtenidos con GPS diferencial para analizar la topografía de las escarpas

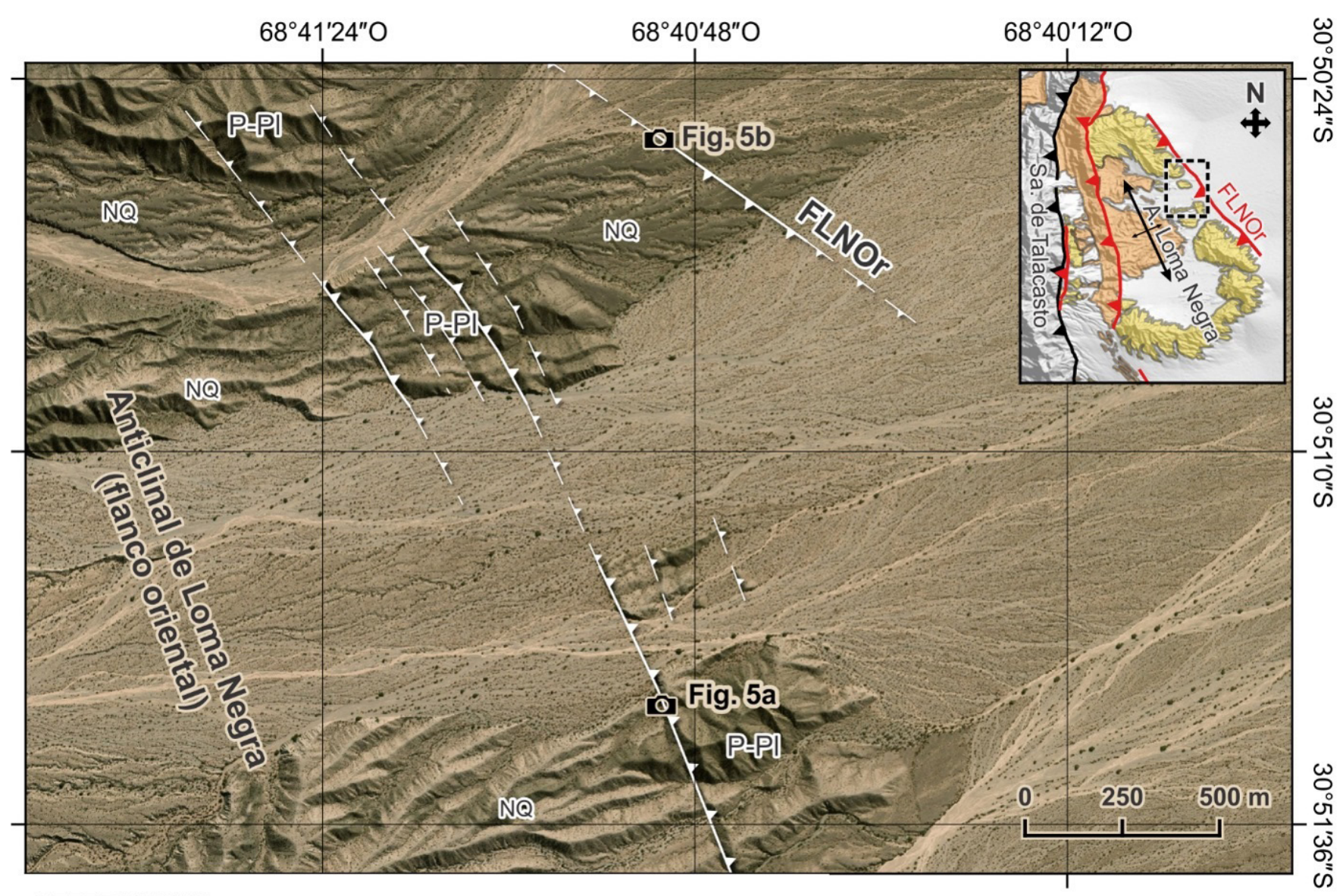

\section{REFERENCIAS}
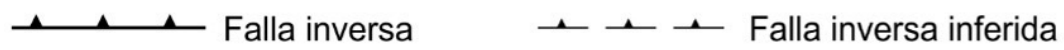

Figura 4 Imagen satelital en la que se indican las fallas inversas con vergencia occidental (flexural slip o retrocabalgamientos) y oriental (falla Loma Negra Oriental FLNOr) en el flanco nororiental del braquianticlinal (recuadro con línea punteada). Se indica además la ubicación de las dos exposiciones naturales identificadas (fotos 5a, 5b). Las fallas afectan conglomerados plio-pleistocenos (P-PI) y depósitos aluviales cuaternarios (NQ). 

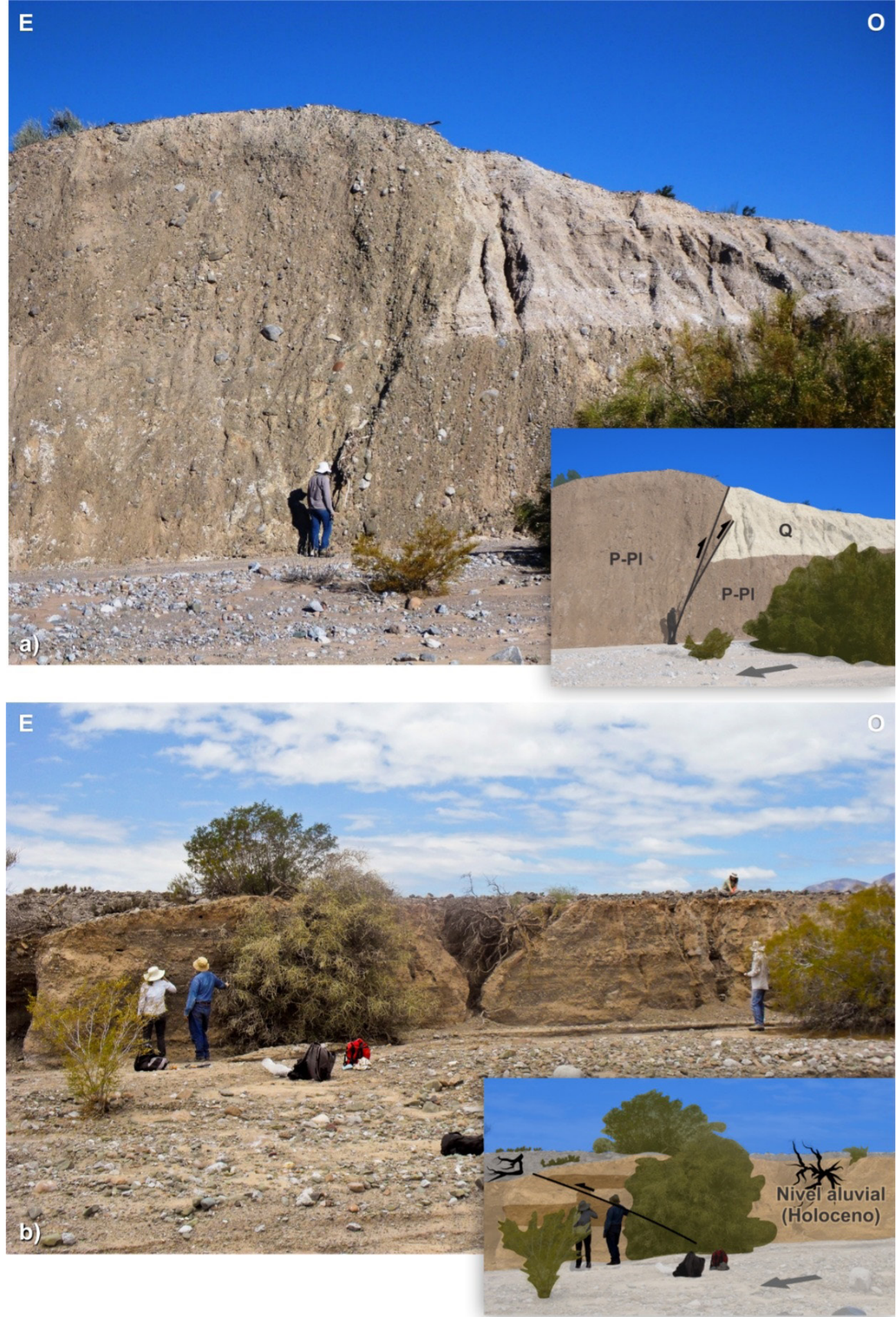

Figura 5 a) Exposición natural de una falla inversa con vergencia occidental de alto ángulo que coloca conglomerados plio-pleistocenos (P-PI) sobre depósitos aluviales del Pleistoceno tardío. b) Vista al sur de la exposición natural en una terraza de acumulación en la margen derecha de un arroyo proveniente de la sierra de Talacasto. La misma muestra la FLNOr, inversa de bajo ángulo y vergencia oriental que desplaza los depósitos fluviales cuaternarios. 
de la falla, se combinaron con la descripción paleosísmica de la exposición natural analizada. Esto proporcionó datos básicos y parámetros de las escarpas reconocidas tales como altura y ángulo máximo de talud que permitieron una caracterización de la estructura.

\section{Análisis paleosísmico de una exposición natural}

A partir del análisis de la exposición natural identificada, se intentó estimar el potencial sismogénico de la FLNOr. El tamaño y la distribución de las deformaciones tectónicas registradas en los niveles aluviales holocenos que constituyen la terraza fluvial permitieron estimar el número mínimo de paleosismos, sus magnitudes, las tasas de deslizamiento y los intervalos de recurrencia.

En esta exposición natural (3050'29.41'S $68^{\circ} 40^{\prime} 51.1$ 1"O) de $\sim 2,7 \mathrm{~m}$ de altura y casi $4 \mathrm{~m}$ de longitud se analizó la cinemática de la falla y las principales características de los depósitos fluviales desplazados (Figura 6a). Se trata de un cabalgamiento de vergencia oriental, con azimut $130^{\circ} \mathrm{y}$ buzamiento $22^{\circ} \mathrm{SO}$. La falla en superficie genera suaves flexuras del terreno, las que muestran la cara libre hacia el este, a favor de la pendiente regional. Un nivel aluvial de la terraza, en el labio hundido del cabalgamiento, fue datado por $O S L$ (3050'29.41"S - 6840'51.11"O), obteniéndose una edad numérica de $8.700 \pm 1.370$ años (Holoceno temprano).

El registro sedimentario expuesto en la pared sur de la terraza de acumulación (Figura 6b) está conformado de base a techo por 5 subunidades depositacionales tabulares prácticamente horizontales que fueron desplazadas por la actividad de la falla:

- S1: Depósito aluvial (aglomerado) conformado por gravas. Clastos imbricados redondeados a subredondeados de calizas (85\%), grauvacas $(10 \%)$ y rocas ígneas $(5 \%)$, matriz sostén, arenas cementadas por carbonatos. El tamaño de los clastos varía entre unos pocos $\mathrm{mm}$ hasta $\sim 10 \mathrm{~cm}$.
- $\quad$ 2: Depósito aluvial (aglomerado) secuencia granocreciente, matriz sostén, pero con mayor porcentaje de clastos que en S1. Clastos imbricados subredondeados a subangulosos de calizas $(80 \%)$, grauvacas $(15 \%)$ y rocas ígneas muy redondeadas (5\%). Muestra una estructura en láminas paralelas.

- S3: Depósito aluvial, matriz sostén. Clastos angulosos, con pobre ordenamiento e intercalaciones de niveles finos. Esta subunidad sólo aparece en el labio hundido de la falla. Calizas $(80 \%)$, grauvacas $(15 \%)$ y rocas ígneas $(5 \%)$.

- S4: Depósito aluvial (aglomerado) matriz sostén, $>50 \%$ de matriz. Clastos redondeados, calizas $(85 \%)$, grauvacas $(10 \%)$ y rocas ígneas $(5 \%)$.

- S5: Cubierta aluvial actual, con clastos y algunos bloques angulosos de grauvacas y calizas.

Las subunidades S1 y S2 están presentes en ambos bloques de la falla, mientras que en el labio elevado la subunidad S3 está ausente. Es posible apreciar que los clastos se alinean con sus ejes mayores paralelos al plano de la falla (Figura 6b, detalle A).

En esta exposición natural se efectuó además el análisis de retrodeformación de cada evento (Figura 7), a modo de identificar la cantidad de deformación producida por cada paleoterremoto. Esta restauración permitió estimar los valores de salto cosísmico para cada evento. En primera instancia, se depositaron las subunidades aluviales S1 y S2 (Figura 7a). Durante el primer evento ocurrido durante el Holoceno, la falla desplazó ambas unidades (S1 y S2) generando una escarpa con la cara libre al este (Figura 7b). Posteriormente se depositó en el bloque hundido el nivel S3, parcialmente derivado de la subunidad S2 ubicada en el bloque elevado (Figura 7c). Asociado a este desplazamiento y como evidencia de este movimiento, se relevó un paleocanal o gotera tectónica (Audemard, 1999) desarrollado paralelo al pie de la escarpa generada por el evento sísmico. Posteriormente se depositó la subunidad S4 que cubrió el terreno regularizando el escarpe, sugiriendo un periodo en el que la tasa de sedimentación fue mayor a la tectónica o un periodo intersísmico 
a)

\section{E}

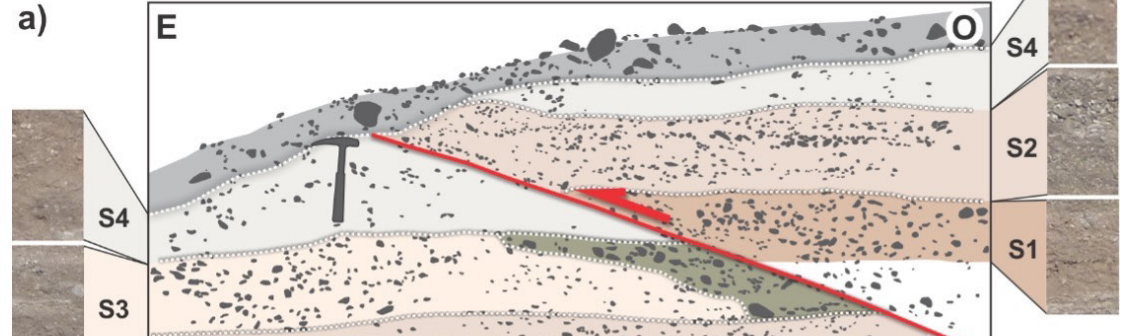
$\therefore 00$

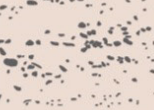

(1)

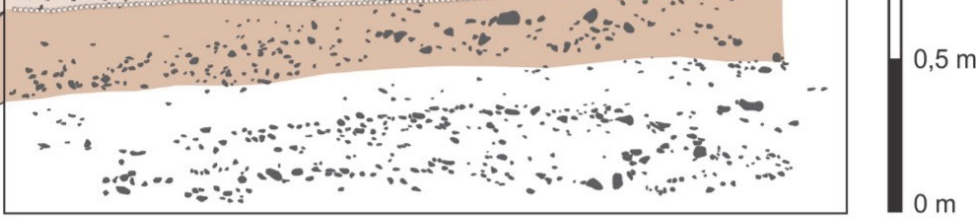

\begin{tabular}{|c|c|c|c|c|c|}
\hline S1 & Subunidad 1 & S3 & Subunidad 3 & S5 & Subunidad 5 \\
\hline S2 & Subunidad 2 & S4 & Subunidad 4 & & 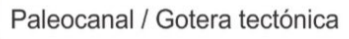 \\
\hline
\end{tabular}
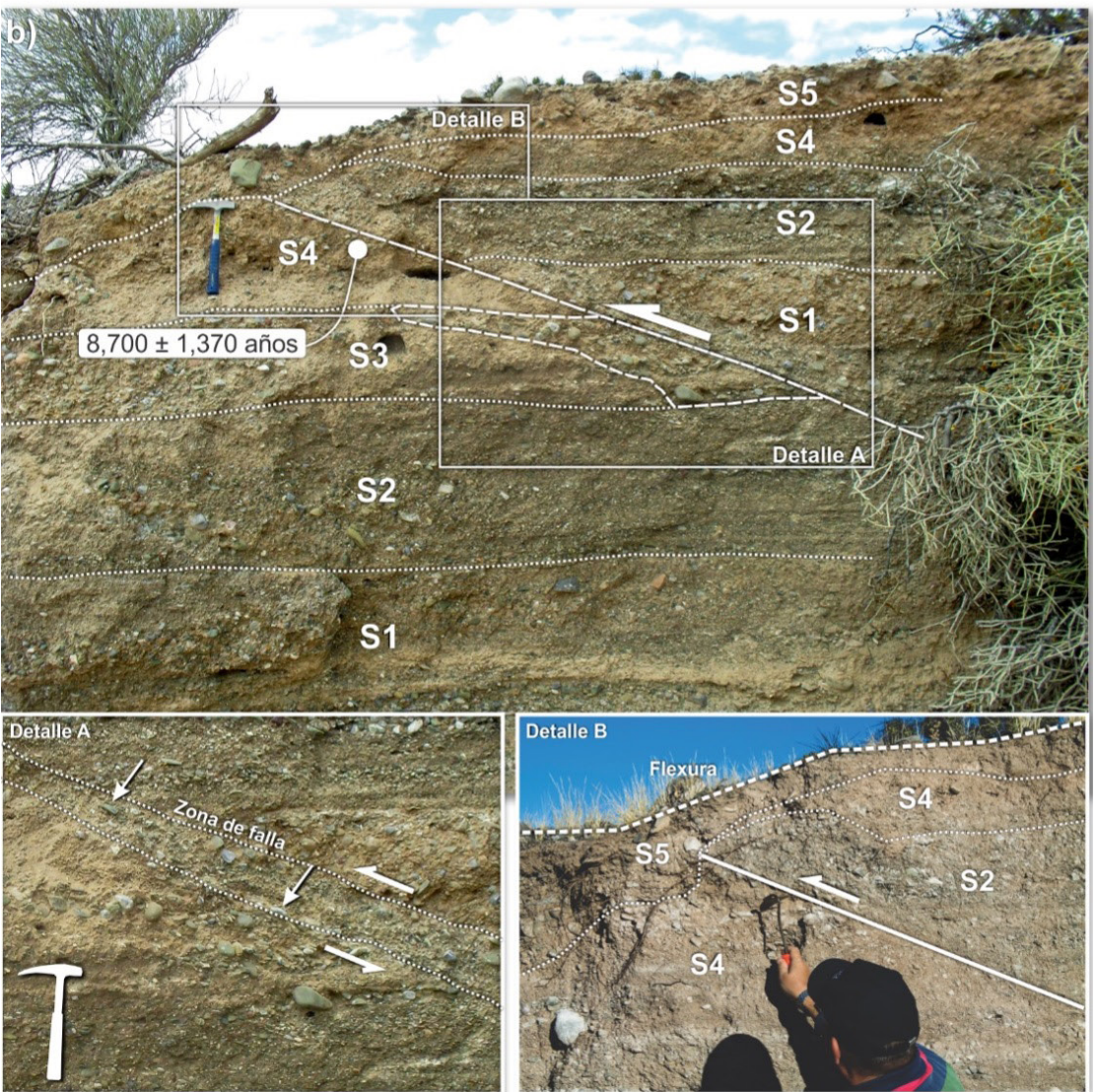

Figura 6 a) Interpretación de la exposición natural en la que se aprecia el desplazamiento de las subunidades que constituyen la terraza de acumulación, b) Fotografía de la exposición con la indicación de las subunidades y la falla que los desplaza. Los recuadros indican sectores ampliados. Detalle A: Clastos orientados con su eje mayor paralelo al plano de falla (señalados por flechas). Detalle B: La falla parece afectar la subunidad S5 (cubierta aluvial reciente) y generar una suave flexura de la superficie, sin cortarla. También se aprecia la deformación de las subunidades S2 y S4 en el bloque elevado y se señala con la herramienta el punto de la toma de muestra para OSL, que arrojó una edad numérica de $8.700 \pm 1.370$ años AP (Holoceno). 
(Figura 7d). Un segundo evento posterior a los $8.700 \pm 1.370$ años desplazó la subunidad S4, cuya escarpa ha sido redondeada y posteriormente se depositó la subunidad S5 que corresponde a un suelo incipiente (Figura 7f). La suave flexura que presenta la superficie actual de la terraza y el pequeño desplazamiento que muestra el nivel S5 podría sugerir la ocurrencia de un tercer evento durante el Holoceno, aunque la falla no cortó la superficie (Figura 6b, detalle B).

El rechazo vertical obtenido para la falla a partir del análisis de las subunidades desplazadas es de $0,9 \pm 0,1 \mathrm{~m}$ para la suma de eventos y el desplazamiento cosísmico sobre el plano de falla es de 1,16 $\pm 0,15 \mathrm{~m}$ por evento (Figura 7).
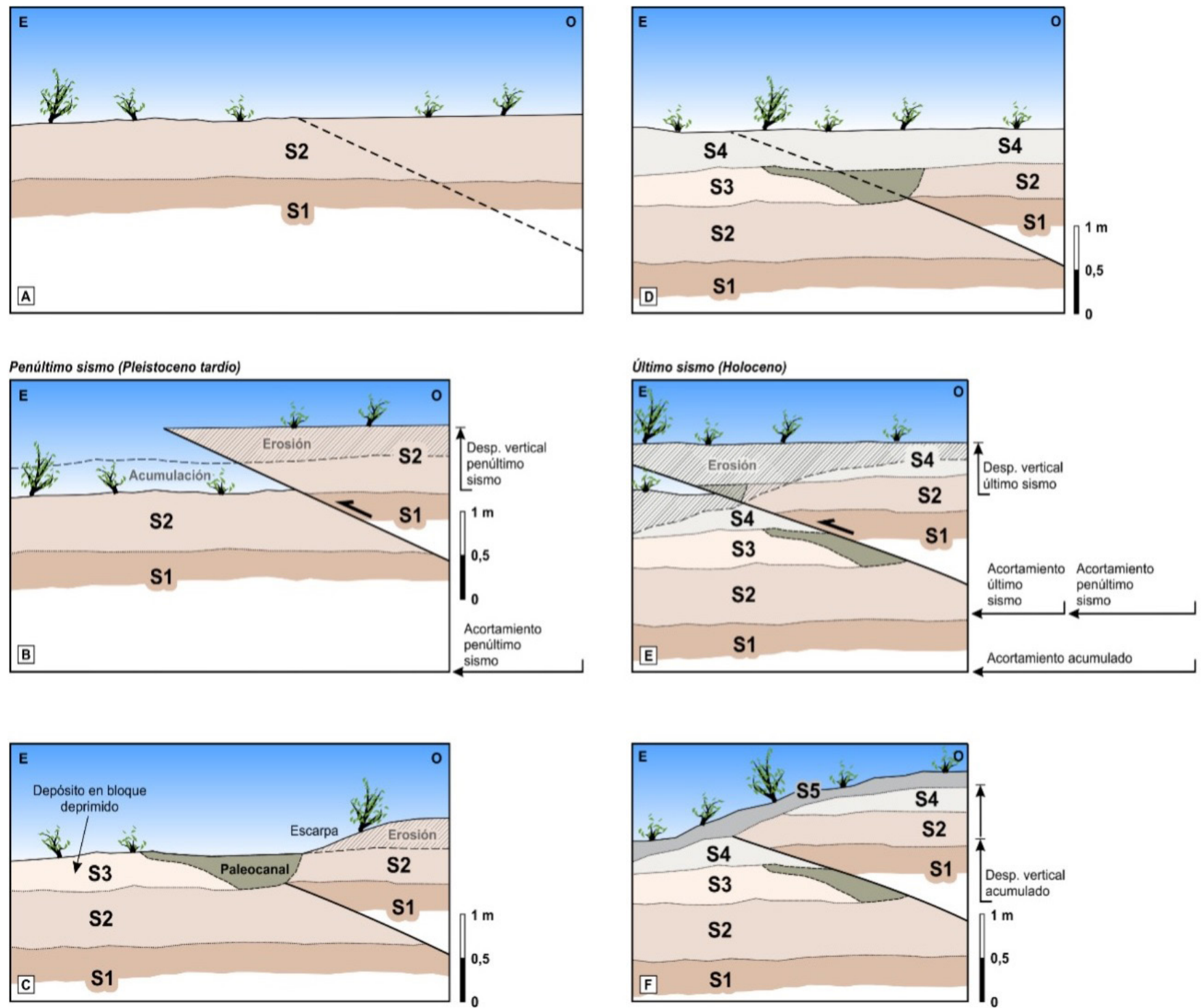

Figura 7 Modelo esquemático de retrodeformación en la exposición natural relevada en la terraza aluvial. Se parte de una estadio inicial durante el Pleistoceno tardío en el que se depositan las subunidades S1 y S2 (a), posteriormente, ocurre un evento sísmico que desplaza ambas subunidades (b), en (c) se muestra la formación de un canal paralelo a la escarpa (gotera tectónica), seguido de un periodo intersísmico o de mayor tasa de depositación que la actividad tectónica en la que se deposita la subunidad S4 (d). Un nuevo evento ocurrido con posterioridad a $8.700 \pm 1.370$ años desplaza la subunidad S4 (e) y finalmente se erosiona la escarpa generada durante este último evento y se deposita el nivel S5 (f). 
Tabla 1. Parámetros (altura y ángulo máximo de talud) medidos en las escarpas A y B.

\begin{tabular}{|c|c|c|}
\hline Escarpas & $\begin{array}{l}\text { A (altura metros- ángulo máximo } \\
\text { de talud) }\end{array}$ & $\begin{array}{l}\text { B (altura metros - ángulo } \\
\text { máximo de talud) }\end{array}$ \\
\hline Norte & $0.92-6^{\circ}$ & $1.41-9^{\circ}$ \\
Centro & $3.1-13^{\circ}$ & \\
Sur & $2.5-10^{\circ}$ & $1.01-10^{\circ}$ \\
\hline
\end{tabular}

\subsection{ANÁLISIS DE ESGARPAS MEDIANTE GPS DIFERENGIAL}

El análisis de la FLNOr se completó con el estudio morfológico-cuantitativo de las escarpas de flexura originadas por la misma en un nivel aluvial cuaternario, mediante los perfiles topográficos de detalle realizados con GPS diferencial, que atraviesan casi ortogonalmente la estructura. Se descartó un control litológico para los cambios de pendiente observados, ya que todos los perfiles fueron efectuados en depósitos aluviales que no presentaban variaciones en sus características litológicas que indiquen un control pasivo.

Los tres perfiles topográficos relevados con precisión centimétrica, tienen azimuts entre $70^{\circ}$ y $80^{\circ}$ ( O-E) es decir que son aproximadamente perpendiculares a las escarpas, denominándose de norte a sur perfiles Norte $(\mathbf{N})$, Centro $(\mathrm{C})$ y $\operatorname{Sur}(\mathrm{S})$, con una equidistancia entre puntos de medición de $10 \mathrm{~m}$ y una longitud aproximadas de $100 \mathrm{~m}$ (Figura $8 \mathrm{a}$ y $8 b$ ). La pendiente general en el sector es de $3^{\circ}$ a $4^{\circ}$.

En el perfil Norte (Figura 8b y 8c) en un recorrido de $90 \mathrm{~m}$ con una diferencia de cota de $\sim 5,3 \mathrm{~m}$ entre los puntos de mayor y menor altura del perfil, se identificaron dos escarpas (A y B). La escarpa B se relaciona espacialmente con la expresión superficial de la FLNOr, analizada en la exposición natural de la terraza. El perfil Centro (Figura 8b y 8c), tiene una extensión de 93 m con una diferencia de cota de $7 \mathrm{~m}$ entre sus puntos extremos. En él se aprecia solo una escarpa con claridad (A) y además un cambio de pendiente que puede considerarse como el inicio de la segunda escarpa (B) identificada en el perfil Norte. La traza del perfil Centro no se continuó más hacia el este porque el terreno es disectado por cauces fluviales que obliteran los resultados. El perfil Sur (Figura 8b y 8c) muestra las dos escarpas (A y B) en un tramo de $93 \mathrm{~m}$ y un desnivel de $6 \mathrm{~m}$ entre ambos extremos. A partir del análisis de los perfiles topográficos, se clasificaron estos cambios de pendiente de la superficie del nivel aluvial, como correspondientes a escarpas multi-eventos posiblemente originados, cada uno de ellos, por un evento de ruptura individual.

De los perfiles se extrajeron los parámetros cuantitativos tales como el ángulo máximo del talud y la altura de las dos escarpas A y B (Figura 8 , Tabla 1).

La escarpa A muestra las mayores alturas y ángulos de talud en las transectas Centro y Sur, hacia el sureste de la trinchera analizada (Tabla 1). La escarpa B tiene alturas cercanas al metro en los perfiles Norte y Sur; ésta no fue interceptada por el perfil Centro por su extensión limitada. No obstante, es posible apreciar que todas presentan un aspecto redondeado, suave y con la cara libre al este.

Con estos datos se estimó la edad de reactivación de la estructura basada en la propuesta de las curvas de regresión que estiman tal edad a partir del principio de que el ángulo máximo de talud de la escarpa es proporcional al logaritmo de la altura.

Se graficaron los valores de pendiente de las escarpas de cada transecta para ver el diseño de la traza de falla, teniendo en cuenta que una falla inversa de bajo ángulo puede romper de diferente manera a lo largo de su traza. Los valores para el primer y segundo evento considerados en cada transecta caen en una región del ábaco muy cercanos entre sí. Tomando las pendientes 

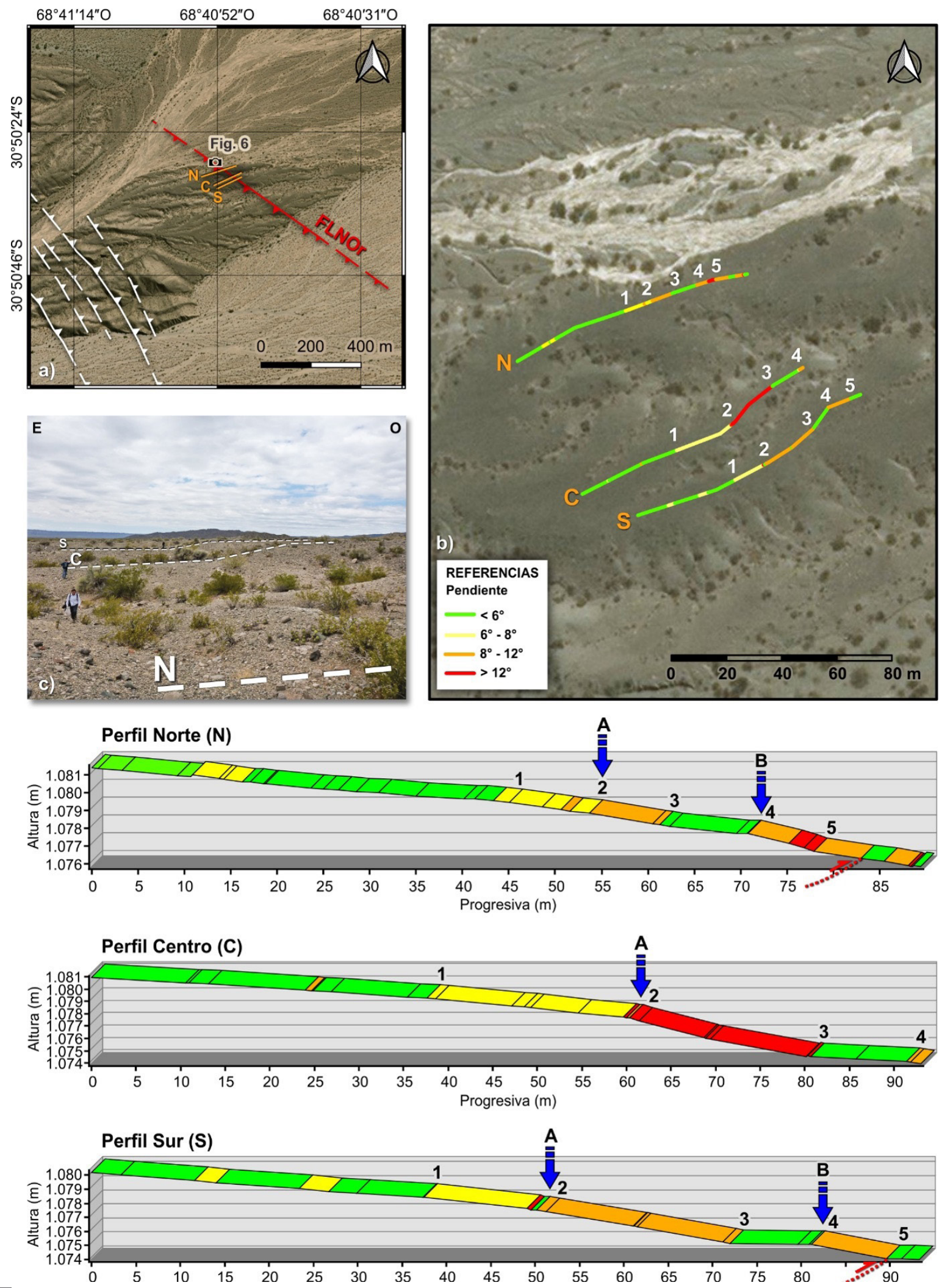

Figura 8 a) Ubicación en una imagen satelital de las tres transectas relevadas con GPS diferencial, aproximadamente perpendiculares a la falla, b) Perfiles relevados y pendientes obtenidas, C) Vista hacia el sur de las escarpas medidas, d) Perfiles topográficos Norte (N), Centro (C) y Sur (S), las flechas indican las escarpas A y B observadas y analizadas. 
de cada escarpa, observadas en los tres perfiles y de acuerdo a la metodología desarrollada por Wallace (1977) y Bucknam y Anderson (1979) mencionada anteriormente, la escarpa A tendría una edad entre 10.000 y 100.000 años y la escarpa B, una edad entre 1.000 y 10.000 años (Figura 9). Esta última es consistente con la edad numérica obtenida para el último nivel aluvial afectado por la falla, de $8.700 \pm 1.370$ años AP.

A partir del análisis efectuado en la exposición natural, se podría estimar la ocurrencia de al menos dos eventos durante el Pleistoceno tardío-Holoceno.

\section{Evaluación de la FLNOr como fuente sismogénica potencial}

A partir del análisis de la exposición natural en la terraza fluvial y el relevamiento efectuado en las escarpas, es posible determinar que la FLNOr posee una expresión superficial de $400 \mathrm{~m}$ de longitud, aunque sobre la base de estudios gravimétricos de detalle (Tejada, 2021), se estima una extensión mayor como estructura ciega, de más de $16 \mathrm{~km}$. Por otro lado, al calcular la magnitud considerando una longitud de ruptura subsuperficial que coincide con todo el flanco oriental del braquianticlinal de Loma Negra, marginado al este en toda su extensión por la FLNOr, se obtiene una longitud de al menos 16,5 km, pudiendo incluso extenderse por más kilómetros (Figura 1d).

Wells y Coppersmith (1994) propusieron una serie de ecuaciones para estimar las magnitudes máximas de un terremoto tanto para fallas superficiales como para fuentes sísmicas subterráneas como fallas ciegas, y para estimar el desplazamiento superficial esperado a lo largo de una falla para un determinado tamaño de terremoto. Las regresiones logarítmicas lineales entre la magnitud del terremoto y la longitud de la ruptura de la superficie, la longitud de la ruptura del subsuelo

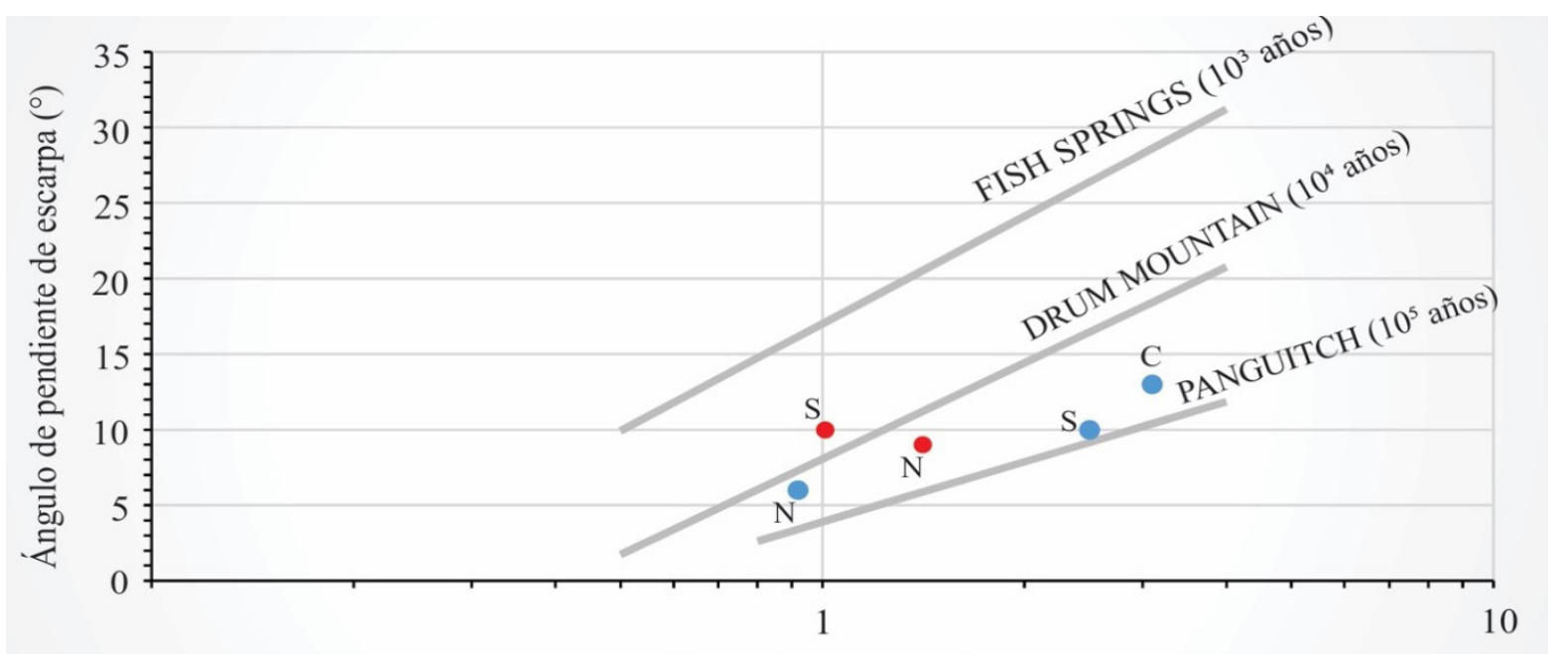

Altura de escarpa (m)

\section{Transecta norte $(\mathrm{N})$, transecta centro $(\mathrm{C})$, transecta sur $(\mathrm{S})$}

\section{Escarpas asociadas a $1^{\circ}$ evento sísmico}

\section{Escarpas asociadas a $2^{\circ}$ evento sísmico}


y el área de la ruptura están bien correlacionadas, mostrando desviaciones estándar de 0,25 a 0,35 unidades de magnitud.

Ecuación de magnitud momento:

- $\mathrm{Mw}=5,08+1,16 * \log \mathrm{L}$ $M w=$ Magnitud momento

$L=$ longitud de ruptura superficial en kilómetros.

Ecuaciones de desplazamiento en metros:

- $\mathrm{Mw}=6,69+0,74 * \log \mathrm{MD}$ $M D=$ máximo desplazamiento

- $\mathrm{Mw}=6,93+0,82 * \log \mathrm{DP}$

$D P=$ desplazamiento promedio en metros:

A partir de estas relaciones, y estimando una longitud de la falla en coincidencia con el flanco oriental del braquianticlinal de Loma Negra, se obtuvo una magnitud máxima probable $\mathrm{Mw}=6,5$, un desplazamiento máximo por evento de $0,56 \mathrm{~m}$ y un desplazamiento promedio de $0,2 \mathrm{~m}$.

Sin embargo, al considerar los valores obtenidos a partir del análisis de la exposición paleosísmica, en donde el desplazamiento MD por evento medido es de al menos $\sim 1 \mathrm{~m}$, la magnitud del sismo máximo probable es mayor a la inferida de acuerdo a la geofísica y a la longitud del flanco oriental afectado por el cabalgamiento $\left(\mathrm{Mw}_{\mathrm{w}} \sim 7\right)$.

La estimación de la tasa de deslizamiento se realizó considerando el desplazamiento cosísmico en el plano de falla correspondientes al último evento identificado en la exposición $(1,01 \pm 0,1$ m) y la datación numérica realizada en el nivel S4 afectado por la falla (8.700 \pm 1.370 años). Para obtener una primera aproximación de la tasa de deslizamiento de la FLNOr, se usaron los valores promedio:

$S R=$ Desplazamiento total $(\mathrm{mm}) /$ tiempo transcurrido (años) $(1.010 \pm 100) /(8.700 \pm 1.370)=0,11 \pm$ $0,07 \mathrm{~mm} / \mathrm{a}$

Es decir que se estimó una tasa de aproximadamente $0,11 \pm 0,07 \mathrm{~mm} /$ año.

Para estimar el intervalo de recurrencia se aplicó la relación de McCalpin (2009):
$\mathrm{RI}=$ Desplazamiento promedio $(\mathrm{dprom})(\mathrm{mm}) /$

$\mathrm{SR}(\mathrm{mm} / \mathrm{a})$ - Creep $(\mathrm{C}=0)$

$(1,16 \pm 0,15) /(0,11 \pm 0,07) \approx 10.000 \mathrm{ka}$.

\section{Discusión y Conclusiones}

Si bien diversos autores definen la neotectónica como los procesos tectónicos que han ocurrido desde el Mioceno-Plioceno (e.g. Winslow, 1986; Slemmons, 1991; entre otros), en el presente trabajo se considera a las deformaciones cuaternarias s.l. como sinónimo de deformaciones neotectónicas (PMA, 2009) y de acuerdo a los criterios también sugeridos por Costa et al. (2006), quienes señalaron que los procesos neotectónicos son aquellos que abarcan las características resultantes del campo de estrés activo (moderno), las estructuras relacionadas con cambios topográficos recientes o en curso y aquellas estructuras que han producido terremotos en el pasado y pueden generar terremotos en el futuro, por lo que se enmarcan en una evaluación de peligro sísmico.

Además, los rasgos geomorfológicos descritos, tales como las escarpas de flexura en la superficie de la terraza fluvial cuaternaria donde la FLNOr está expuesta, muestran que existe un control activo del terreno. Las edades estimadas para estas escarpas mediante el análisis de sus alturas y ángulos máximos de talud, permiten sugerir que la estructura ha tenido actividad tectónica en los últimos 100.000 años y hasta el Holoceno. Allmendinger et al. (1990) atribuyeron como principal mecanismo de plegamiento en el frente orogénico andino a la propagación de fallas. La disposición submeridional y con vergencia oriental de bajo ángulo de las estructuras presentes en el braquianticlinal son compatibles con un mecanismo de evolución de la deformación en el cual las láminas de cabalgamiento principales se propagan hacia el antepaís: primero se habría originado la lámina de cabalgamiento que eleva la sierra de Talacasto y coloca rocas del Ordovícico sobre sedimentitas neógenas. Más hacia el este se ubica la falla Loma Negra Occidental que dispone rocas asignadas al Neógeno sobre depósitos plio-pleistocenos. 
En el flanco oriental del braquianticlinal se ubica la FLNOr que afecta a depósitos de edad pleistocena-holocena. Las escarpas identificadas en el área de estudio poseen una longitud aproximada de sólo $400 \mathrm{~m}$ y desaparecen progresivamente tanto hacia el norte como hacia el sur, posiblemente por la sedimentación de los niveles aluviales que descienden del frente montañoso combinado con erosión fluvial en el piedemonte de la estructura plegada.

La interpretación paleosísmica de la exposición natural de la FLNOr sugiere la ocurrencia de dos eventos, uno durante el Pleistoceno tardío que afectó los niveles aluviales $\mathrm{S} 1$ y $\mathrm{S} 2$ y un segundo evento posterior a la depositación del nivel aluvial S4 datado en $8.700 \pm 1.370$ años AP (Holoceno temprano). De acuerdo a los datos de campo y relaciones empíricas, el máximo sismo probable generado por la FLNOr tendría una magnitud mínima de $\mathrm{Mw} \sim 6,5( \pm 0.1)$ y posiblemente más próxima a una $\mathrm{Mw} \sim 7$, con un periodo de recurrencia de $\sim 9.000$ años o quizás menor. Estos valores son consistentes con aquellos obtenidos por diversos autores en el área de Precordillera Central y Oriental.

Paredes et al. (1997) y Paredes y Perucca (2000) señalaron que al sur del área de estudio, el sistema de falla Blanquitos habría tenido actividad durante el Pleistoceno superior-Holoceno, de acuerdo a la deformación de travertinos ubicados en el plano de falla, cuya edad ${ }^{14} \mathrm{C}$ es de $28.422 \pm 1.335$ años AP. Sin embargo, estos autores no estimaron su recurrencia ni el potencial sismogénico de esta estructura.

Perucca et al. (2015) estimaron para el sistema de falla La Cantera, un cabalgamiento también con vergencia oriental ubicado al oeste del área de estudio en Precordillera Central, un intervalo de recurrencia de al menos $2.000 \pm 500$ años para sismos de moderada magnitud en los últimos 11.000 años. En el extremo sur de la depresión tectónica de Matagusanos-Maradona-Acequión, también en Precordillera Central, Audemard et al. (2016) señalaron al menos dos eventos para la falla Acequión (también con vergencia al este) en los últimos 14.000 años con intervalos de recurrencia estimados en $6.000 \pm 2.000$ años en promedio, con un rechazo vertical del orden de $1 \mathrm{~m}$ por evento, una magnitud mayor que 7 y un desplazamiento sobre el plano de falla del orden de $2 \mathrm{~m}$ por evento.

Por otro lado, en el ámbito de Precordillera Oriental, al sureste del área de estudio, Siame et al. (2002) estimaron para la falla Loma de Las Tapias un sismo máximo de $\mathrm{Mw}_{\mathrm{w}} \sim 7,3( \pm 0,1)$ y un intervalo de recurrencia de $2.400 \pm 1.500$ años.

Finalmente, los datos obtenidos en este trabajo deben ser ajustados con nuevas edades numéricas y futuros estudios de detalle que permitan determinar con mayor precisión la longitud de esta estructura (expuesta + soterrada) y que reduzcan la incertidumbre en los resultados obtenidos en este trabajo referidos principalmente a: tasas de deslizamiento, intervalos de recurrencia y magnitud máxima probable, necesarios para una mejor caracterización de esta estructura como potencial fuente sismogénica.

\section{Agradecimientos}

Este trabajo se realizó durante la ejecución de la beca doctoral otorgada por CONICET a la Lic. Flavia Tejada y fue financiado por los Proyectos IPGH 2018, CICITCA 2018-2019 y AGENCIA 2016-Préstamo BID otorgados a la Dra. L. Perucca. Se agradece también a los revisores Claudio Limeira, María Ortuño y Fernando Hongn que contribuyeron a mejorar este trabajo.

\section{Referencias}

Alcacer Sánchez, J., Perucca, L., 2017, Análisis Neotectónico en el piedemonte oriental de Cordillera Frontal, Andes Centrales, San Juan, Argentina: Revista Geociencias, 36(4), 691-702. https://doi.org/10.5016/ geociencias.v36i4.12219

Allmendinger, R. W., Figueroa, D., Snyder, D., Beer, J., Mpodozis, C., Isacks, B. L., 1990, Foreland shortening and crustal balancing 
in the Andes at 308S latitude: Tectonics, 9, 789- 809. https://doi.org/10.1029/ TC009i004p00789

Alvarado, P., Beck, S., 2006, Source characterization of the San Juan (Argentina) crustal earthquakes of 15 January 1944 (Mw 7.0) and 11 June 1952 (Mw 6.8): Earth and Planetary Science Letters, 243(3-4), 615-631. https://doi.org/10.1016/j.epsl.2006.01.015 Álvarez-Marrón, J., Rodriguez-Fernandez, R., Heredia, N., Busquets, P., Colombo, F., Brown, D., 2006., Neogene structures overprinting Palaeozoic thrust systems in the Andean Precordillera at 30S latitude: Journal of the Geological Society, 163, 949-964. https:// doi.org/10.1144/0016-76492005-142

Anderson, M., Alvarado, P., Zandt, P., Beck, S., 2007, Geometry and brittle deformation of the subducting Nazca plate, Central Chile and Argentina: Geophysical Journal International 171, 419-434. https://doi. org/10.1111/j.1365-246X.2007.03483.x

Audemard, F., 1999, Morpho-structural expression of active thrust fault systems in the Humid Tropical Foothills of Colombia and Venezuela: Zeitschrift fur Geomorphologie 118, 1-18.

Audemard M., F., Perucca L., Pantano, A., Ávila, C., Onorato, M.R., Vargas, H., Alvarado, P., Viete, H., 2016, Holocene compression in the Acequión valley (Andes Precordillera, San Juan province, Argentina): Geomorphic, tectonic, and paleoseismic evidence: Journal of South American Earth Sciences, 67,140-157. https://doi.org/10.1016/j. jsames.2016.02.005

Bastías, H., 1985., Fallamiento Cuaternario en la región sismotectónica de Precordillera. San Juan, Universidad Nacional de San Juan, Facultad de Ciencias Exactas, Físicas y Naturales, Tesis Doctoral, 147 p.

Bastías, H., Weidmann, N., Pérez, M., 1984, Dos zonas de fallamiento Pliocuaternario en la Precordillera de San Juan. IX Congreso Geológico Argentino, 2, 329-341
Blanc, P. A., Tejada, F., Perucca, L. P., Espejo, K., Lara, G., Vargas, N., 2020, Morphotectonic analysis of two axial tributary basins of the San Juan river controlled by the Precordillera fold and thrust belt, Central Andes of Argentina: Journal of South American Earth Sciences, 98, 102441. https://doi. org/10.1016/j.jsames.2019.102441

Boyer, S.E., Elliott, D., 1982, Thrust systems: Bulletin of the American Association of Petroleum Geologists, 66, 1196-1230.

Bucknam, R. G., Anderson, R. E., 1979, Estimation of fault-scarp ages from a scarpheightslope-angle relationship: Geology, 7, 11-14. https://doi.org/10.1130/00917613(1979)7<11:EOFAFA>2.0.CO;2

Costa, C., Rockwell, T., Paredes, J., Gardini, C., 1999, Quaternary deformation and seismic hazard at the Andean orogenic front $\left(31^{\circ}-33^{\circ}\right.$, Argentina): A paleoseismological perspective (Extended Abstracts) in $4^{\circ}$ International Symposium on Andean Geodynamics: Paris, 187-191.

Costa, G., Machette, M., Dart, R., Bastías, H., Paredes, J., Perucca, L., Tello, G., Haller, K., 2000, Map and Database of Quaternary Faults and Folds in Argentina, U.S. Geological Survey, Open-File Report 00-0108, 75 p. https://doi.org/10.3133/ofr00108

Costa, C., Audemard, F., Bezerra, F., Lavenu, A.A., Machette, M., París, G., 2006, An overview of the main Quaternary deformation of South America: Revista de la Asociación Geológica Argentina 61, 461-479.

Costa, C., Alvarado, A., Audemard, F., Audin, L., Benavente Escóbar, G., Bezerra, F., Cembrano, J., González, G., López, M., Minaya, E., Santibanez, I., Garcia Pelaez, J., Arcila, M., Pagani, M., Pérez, I., Delgado, F., Paolini, M., Garro, H., 2020,. Hazardous faults of South America; compilation and overview: Journal of South American Earth Sciences, 104. 102837. https://doi. org/10.1016/j.jsames.2020.102837

Furque, G., González, P., Caballé, M., 1998, 
Descripción de la hoja geológica 3169-II, San José de Jáchal (Provincias de San Juan y La Rioja), 1:250,000: Servicio Geológico y Minero Argentino Boletín, mapa con texto.

Japas, M.S., 1998, Aporte del análisis de fábrica deformacional al estudio de la faja orogénica andina. Homenaje al Dr. Arturo J. Amos: Revista de la Asociación Geológica Argentina, 53, 15.

Japas, M., Ré, G., Oriolo, S., Vilas, J., 2016, Paleomagnetic data from the Precordillera fold and thrust belt constraining Neogene foreland evolution of the Pampean flatslab segment (Central Andes, Argentina): Geological Society, London, Special Publications, 425(1), 81-105. https://doi. org/10.1144/sp425.9

Jordan, T., Isacks, B., Allmendinger, R., Brewer, J., Ramos, V., Ando, C., 1984, Andean tectonics related to geometry of subducted Nazca plate: Geological Society of America Bulletin, 94, 341-361. https://doi. org/10.1130/0016-7606(1984)95<880:ATR $\mathrm{TGO}>2.0 . \mathrm{GO} ; 2$.

Jordan, T.E., Allmendinger, R.W., Damanti, J.F., Drake, R.E., 1993, Chronology of motion in a complete thrust belt: the Precordillera, 30-31 ${ }^{\circ}$, Andes Mountains: Journal of Geology, 101, 137-158. http://dx.doi. org/10.1086/648213

Kay, S.M., Mpodozis, C., 2002, Magmatism as a probe to the Neogene shallowing of the Nazca plate beneath the modern Chilean flat slab: Journal of South American Earth Sciences 15, 39-59. https://doi. org/10.1016/S0895-9811(02)00005-6

Kendrick, E., Bevis, M., Smalley, R.J., Brooks, B.,Vargas, R.B., Lauría, E., Fortes, L.P.S., 2003, The Nazca-SouthAmerica Euler Vector and its Rate of Change: Journal of South American Earth Sciences, 16. 125-131. https://doi.org/10.1016/ S0895-981 1(03)00028-2

McCalpin, J. P., 2009, Paleoseismology : Amsterdam, Academic Press-Elsevier, 848 p.
Milana, J. P., 2003, Paleoambientes y magnetoestratigrafía del Neógeno de la Sierra de Mogna y su relación con la Cuenca de Antepaís Andina: Revista de la Asociación Geológica Argentina, 58 (3), 447-473.

Ocaña, R., Flores, D., Alcayaga, G., Suvires, G.M., 2017, Geomorphology of Talacasto alluvial fan, Precordillera of San Juan, Argentina: Journal of Maps, 13(2), 929-935. https:// doi.org/10.1080/17445647.2017.1409138

Ortiz, A., Zambrano, J.J., 1981, La provincia geológica Precordillera Oriental, en $8^{\circ}$ Congreso Geológico Argentino: San Luis, Actas 3, 59-74.

Paredes, J., Perucca, L., Tello, G., 1996, Fallas activas en el bolsón de Matagusanos, en $12^{\circ}$ Congreso Geológico de Bolivia: Tarija, Bolivia, Actas 3, 1155-1164.

Paredes, J., Perucca, L., Tello, G., 1997, Fallamiento cuaternario en elárea Blanquitos, departamento Ullùm, San Juan, Argentina, en $2^{\circ}$ Jornadas de Geología de Precordillera: San Juan, 168-173.

Paredes, J., Perucca. L., 1999, Fallas modernas en el piedemonte oriental de la sierra de Talacasto, Precordillera Central, San Juan: en $14^{\circ}$ Congreso Geológico Argentino: San Juan, Actas 1, 260-262.

Paredes, J., Perucca, L., 2000, Fallamiento cuaternario en la depresión de Matagusanos, Argentina: Revista Asociación Geológica Argentina, 55 (1-2), 23-30.

Perucca, L. 1990, Sistema de Fallamiento La Dehesa-Maradona-Acequión, San Juan, Argentina, en $11^{\circ}$ Congreso Geológico Argentino, San Juan, Actas 2, 431-434.

Perucca, L., Paredes, J., 2003, Fallamiento Guaternario en La Zona de La Laja y su Relación con el terremoto de 1944, Departamento Albardón, San Juan, Argentina: Revista Mexicana de Ciencias Geológicas, 20(1), 20-26.

Perucca, L. P., Vargas, H.N., 2014,Neotectónica de la provincia de San Juan, centro-oeste de Argentina: Boletín de la Sociedad Geológica 
Mexicana, 66(2), 291-304. https://doi. org/10.18268/bsgm2014v66n2a6

Perucca, L., Audemard F., Pantano, A., Avila, C., Onorato, M.R., Vargas, H.N., 2013, Fallas cuaternarias con vergencias opuestas entre Precordillera Central y Oriental, Provincia de San Juan: Revista de la Asociación Geológica Argentina, 70 (1), 291-302.

Perucca, L., Pantano, A., Vargas, H. N., 2014, El braquianticlinal de Loma Negra, una estructura de plegamiento cuaternaria en Precordillera Central, provincia de San Juan: Revista de la Asociación Geológica Argentina, 71(3), 427-433.

Perucca, L., Rothis, M., Bezerra, F., Vargas, N., Lima, J., 2015, Late Quaternary evolution of the La Cantera Fault System (Central Precordillera, Argentina): a morphotectonic and paleoseismic analysis. Tectonophysics 661, 200-209 https://doi.org/10.1016/j. tecto.2015.08.041

Pilger, JR., R.H., 1981, Plate reconstructions, aseismic ridges, and low-angle subduction beneath the Andes: Geological Society of America Bulletin, 92(7), 448-456. https://doi. org/10.1130/0016-7606(1981)92<448:prar al>2.0.co;2

Proyecto Multinacional Andino, PMA, 2009, Geociencia para las comunidades andinas, Atlas de deformaciones cuaternarias de los Andes. Servicio Nacional de Geología y Minería, Publicación Geológica Multinacional 7, 104-110. Santiago.

Ramos, V. A., Jordan, T. E., Allmendinger, R. W., Mpodozis, C., Kay, S. M., Cortés, J. M., Palma, M. A., 1986, Paleozoic terranes of the Central Argentine-Chilean Andes: Tectonics, 5, 855-880. https://doi.org/10.1029/ TC005i006p00855

Ramos, V.A., 1988, The tectonics of the Central Andes; $30^{\circ}$ to $33^{\circ} \mathrm{S}$ latitude: Geological Society of America, Special Paper 218, 31-54.

Ramos, V.A., 1997, El Segmento de Subducción Subhorizontal de los Andes Centrales
Argentino-Chilenos: Acta Geológica Hispánica, 32 (7), 5-16.

Ramos, V.A., 1999, Los depósitos sinorogénicos terciarios de la región Andina Geología Argentina, Instituto de Geología y Recursos Minerales, Geología Argentina, Anales 29 (22), 651-682.

Ramos, V., Cegarra, M., Lo Forte, G., Comínguez, A., 1997, El frente orogénico en la Sierra de Pedernal (San Juan Argentina): su migración a través de los depósitos orogénicos, en $8^{\circ}$ Congreso Geológico Chileno: Antofagasta, Chile, Actas 111, 1709-171.

Ré, G.H., Japas, M.S., Barredo, S.P., 2001, Análisis de fábrica deformacional (AFD): El concepto fractal cualitativo aplicado a la definición de lineamientos cinemáticos neógenos en el Noroeste Argentino: Avances en Microtectónica: Asociación Geológica Argentina, Serie D: Publicación Especial 5, 75-82.

Sagripanti, G. L., Villalba, D., Grosso, M. V., Daga, R. B., 2003, Análisis morfológico de escarpas, aplicado a la reconstrucción de la sismicidad prehistórica de la falla Las Lagunas, Sampacho, Córdoba, en $2^{\circ}$ Congreso Nacional de Guaternario y Geomorfología: Tucumán, Actas 1, 369- 377.

Siame, L.L., Bellier, O., Sébrier M., Bourlès, D.L., Leturmy, P., Perez, M., Araujo, M., 2002, Seismic hazard reappraisal from combined structural geology, geomorphology and cosmic ray exposure dating analyses: the Eastern Precordillera thrust system (NW-Argentina): Geophysical Journal International, 150(1), 241-260. https://doi. org/10.1046/j.1365-246x.2002.01701.x

Siame, L.L., Bellier, O., Sébrier, M., Araujo, M., 2005, Deformation partitioning in flat subduction setting: Case of the Andean foreland of western Argentina $\left(28^{\circ} \mathrm{S}-33^{\circ} \mathrm{S}\right)$ : Tectonics, 24 (5), 1-24. http://dx.doi. org/10.1029/2005TC001787

Siame, L., Bellier, O., Sebrier, M., 2006, Active tectonics in the Argentine Precordillera and 
Western Sierras Pampeanas: Revista de la Asociación Geológica Argentina, 61 (4), 604-619.

Slemmons, D.B., 1991, Introduction. In Burton Slemmons, D., Engdahl,E. R., Zoback,Mark D., Blackwell, D.D. (Ed.) Neotectonics of North America: Geological Society of America, 1-20 p. https://doi.org/10.1130/ dnag-csms-neo. 1

Tejada Recabarren, F., 2021, Análisis de la actividad tectónica cuaternaria en el piedemonte oriental de la Sierra de Talacasto, Precordillera Central, provincia de San Juan: San Juan , Argentina, FGEFN-UNSJ, Tesis doctoral.

Tejada Recabarren, F. E., Onorato, M. R., Fernandez, G., 2018, Aplicación de índices para el análisis morfotectónico y evolutivo del paisaje en el piedemonte oriental de la Sierra de Talacasto y Lomas de Jayampes, San Juan, en $7^{\circ}$ Congreso Argentino de Cuaternario y Geomorfología: Puerto Madryn, 18-21.

Vigny, C., Rudloff, A., Ruegg, J. C., Madariaga, R., Campos, J., Alvarez, M., 2009, Upper plate deformation measured by GPS in the Coquimbo Gap, Chile: Physics of the Earth and Planetary Interiors, 175, 86-95. http:// dx.doi.org/10.1016/j.pepi.2008.02.013

Villalba, D., Sagripanti, G., 2014, Análisis morfológico de escarpas asociadas a una falla de intraplaca con actividad cuaternaria: falla Las Lagunas, Córdoba: Revista de la Asociación Geológica Argentina, 71 (1), 82-91.

Von Gosen, W., 1992, Structural evolution of the Argentine Precordillera: the Rio San Juan section: Journal of Structural Geology, 14 (6), 643-667. https://doi. org/10.1016/0191-8141(92)90124-f

Wallace, R. E., 1977, Profiles and ages of young fault scarps, north-central Nevada: Geological Society of America Bulletin,88(9),1267-1281.http:/ / dx.doi. org/10.1130/0016-7606(1977)88\%3C1267: PAAOYF\%3E2.0.GO;2

Wells, D.L., Coppersmith, K. J., 1994, New empirical relationship among magnitude, rupture length, rupture width, rupture area, and surface displacement: Bulletin of Seismological Society of America, 84(3), 974-1002.

Winslow, M.A., 1986, Neotectonics: concepts, definitions and significance: New York, John Wiley \& Sons, 1, 1-5.

Yeats, R., Sieh,K., Allen,C., 1997, The geology of earthquakes: Oxford University Press, 568 p.

Zapata, T.R., Allmendinger, R.W., 1996, ThrustFront Zone of the Precordillera, Argentina: A Thick-Skinned Triangle Zone: American Association of Petroleum Geologists Bulletin, 80 (3), 359-381. https://doi. org/10.1306/64ED87E6-1 724-11D78645000102C1865D 